\title{
The Intellectual Property Protection of Intangible Cultural Heritage
}

\author{
Xiaosu Xing \\ Law school, Shandong Normal University, Ji'nan Shandong, 250100, China
}

Keywords: Intangible cultural heritage, Intellectual property, Protection ways

\begin{abstract}
In the field of private law, intellectual property and intangible cultural heritage have the rather high similarity; therefore it determines that intellectual property protection in the current private law legal system is the most convenient and reasonable protection mode for intangible cultural heritage private law protection. Of course, there are various types of intangible cultural heritages, which should be distinguished based on types and applicable in protection of copyright, trademark right and trade secret right, respectively.
\end{abstract}

\section{The Legitimacy of Intangible Cultural Heritage Intellectual Property Protection}

\section{The Compatibility of Protective Objects of the Two.}

Intellectual property is the legal rights enjoyed by people for the intellectual and creative achievements in the field of science and technology and literature and art and the identifying markers and outcomes in the field of industry and commerce. The intellectual property is the knowledge product of object, which is reflected as certain information and is intangible and replicable. Intangible cultural heritage is not only the wisdom outcome created and inherited by specific ethnic group or a collective community in a particular area, but also the product of intellectual creation. The object of intangible cultural heritage, as an intellectual achievement, is compatible with the object of intellectual property protection. Both share the characteristics of intangible and replicable, so using intellectual property legal system to protect intangible cultural heritage protection is a more appropriate choice. In addition, the article 44of China's "Intangible Cultural Heritage Protection Law" stipulates: "the use of intangible cultural heritage related to intellectual property rights, is applicable for relevant laws and administrative regulations," which also affirmed the legitimacy of utilizing intellectual property legal system to protect intangible cultural heritage from the legislative level.

\section{The Similarity of Right Content of the Two.}

The content of intellectual property includes personal rights as well as property rights. It is most evident in copyright legal system. The reason for giving property right to right holder is for motivating creation behavior of the right holder and improving the level of innovation of the whole society and promoting the continuous development of society. The vest of personal rights does not only reflect the respect for the creative act of right holder. What even more important is the intellectual products created by right holder is firstly reflected as a spiritual product, which is the ideological and spiritual extension of the right holder who should be entitled to a certain moral rights, namely personal rights. Intangible cultural heritage also has these characteristics. Firstly, intangible cultural heritage is the spiritual wealth created collectively by a national or a group over the long history. It is also manifested as a spiritual product, so groups which created it or their successors should enjoy a certain moral rights; secondly, intangible cultural heritage at the same time is also economical. As we all know, our country folk literature "Mulan" was made into a Hollywood movie, which was a very popular animated film in the world and achieved a dramatic profit, while China, as the creating place of "Mulan", has not obtained any benefits. This is certainly unfair. The fact proves that the intangible cultural heritage not only has the economic value and the creating groups or their inheritors should enjoy the property rights, but also proves necessity and legitimacy of intellectual property protection over intangible cultural heritage. 


\section{The Intellectual Property Protection over Intangible Cultural Heritage Being Helpful for Its Development and Inheritance.}

Intangible cultural heritage is different from other cultural offerings, of which its biggest feature lies in its dynamic feature, namely the intangible cultural heritage is not static. It will continue to be innovated and developed in its inheritance process, and will always go on. Therefore, the development and inheritance is the soul of intangible cultural heritage. Only keeping pace up with the development of society, intangible cultural heritage can have a wider living space and is likely to be passed along. And only when it is inherited from generation to generation, intangible cultural heritage can be actually protected. However, due to the vulnerability of intangible cultural heritage and the strong impact of modern civilization, the survival space of the intangible cultural heritage space is getting smaller and smaller. In 2011 China published and implemented "Intangible Cultural Heritage Protection Law", in which stipulates the identification and protection system for inheritors, which no doubt plays a very important role in promoting the inheritance of intangible cultural heritage, but I believe that, "Intangible Cultural Heritage Protection Law "as the public law, realized exogenous protection over inheritors, while intellectual property legal system as a private law, is endogenous protection for inheritors by giving moral rights and property rights to them so that they can obtain spiritual satisfaction and capital gains so as to encourage further innovation and inheritance. In compared with exogenous protection, the endogenous protection as intellectual property legal system is more beneficial for the development and inheritance of intangible cultural heritage.

\section{Copyright Protection of Intangible Cultural Heritage}

The types of intangible cultural heritage that can be included in copyright protection.

The protected object of copyright law is work. The so-called work is an intellectual and creative achievement that reflects the creators' ideology or emotion. It has three elements: first, such wisdom achievement belongs to the field of literary, art and science; secondly, it must be original. The so-called originality means that the "completion of a work should be the outcome of author's own choice, selection, arrangement, design and description, which neither is copied from an existing form, nor it is deduced from the established pattern or program. Finally, the intellectual outcome must be able to be reproduced in a tangible form. Thus, not all forms of intangible cultural heritage are applicable to copyright protection.

\section{Subject of Right.}

Specific nation or regional groups.

Many scholars believe that the creation subject of the intangible cultural heritage is uncertain, and therefore question the legitimacy of the protection by "Copyright Law" over intangible cultural heritage protection. In fact, the creation subject of intangible cultural heritage actually can be determined, but not like the "Copyright Law", by which the protected work is identified as a specific individual. This is also determined by the dynamic feature of intangible cultural heritage. The creative process of intangible cultural heritage is a process of inheritance from generation to generation, which make it have the characteristics of creation subject being as collective. As a specific ethnic group or collective group in a particular region, they should enjoy the copyright rights of their creations. It is entirely consistent with the basic principles of "Copyright Law". But there is one problem: as a collective creative subject, how can they claim rights? I think we can learn from the litigation representative system in class action. The declaration subject of intangible cultural heritage, as the representative, participates in the enforcement and protection of the right of intangible cultural heritage.

Inheritors. Inheritor is the critical subject in intangible cultural heritage protection

The quality of inheritor protection directly affects the survival and development of intangible cultural heritage. Inheritors pay out creative work in organizing, spreading, adaptation, commenting and other heritage activities and certainly deserve the copyright to their creative achievements. However, the legal status of inheritors is different from the legal status of the specific nations or groups, as the creative subject. On the one hand, inheritors, as a member pf collective creator, enjoy 
the rights of collective copyright; on the other hand, inheritors enjoy the individual copyright to their subsequent creations.

\section{Right Acquirement.}

Copyright in most countries of the world is acquired automatically, namely, copyright is generated since the date that the work was produced, without any formality. China is no exception. But there will be some problems for the application of the principle of automatic obtaining of copyright into intangible cultural heritage, it is recommended that the copyright of intangible cultural heritage adopts the principle of registration, meaning that the declaration subject as creation subject register in copyright office. After registration is completed, the specific nation or group as creative subject can enjoy copyright of intangible cultural heritage. Of course, the principle of registration is only applicable only for collective copyright right of intangible cultural heritage, and the personal copyright of inheritors is still applicable in the principle of automatic acquisition. For the protection term of the right, I agree with the view of most scholars, considering the inheritance and development of intangible cultural heritage, we should adopt the principle of long-term protection.

\section{Trademark Right Protection of Intangible Cultural Heritage}

\section{The Advantages of Intangible Cultural Heritage Trademark Right Protection.}

Adopting the model of trademark right to protect intangible cultural heritage has unparalleled advantages than other types of intellectual property rights: firstly, the trademark application and registration is different from patent because it does not require the novelty and inventiveness. And most intangible cultural heritage has entered into the public domain and lost the novelty and inventiveness, which is a major obstacle for intangible cultural heritage to apply patent, but there are no problems in registering trademarks; secondly, despite that trademark has a decade of protection term, yet the protection term can be renewed, and there is no limit in times, which is consistent with the characteristics that intangible cultural heritage requires long-term protection; finally, utilizing trademark right protection mode can also promote the commercialization of intangible cultural heritage and make it achieve higher economic returns. In fact, there were cases of using trademark right to protect intangible cultural heritage in China in last century.

\section{The Choice of Realistic Ways.}

For operation modes in practice, I think we can divide them into two cases: one is the intangible cultural heritage clearly belonging to an individual (or an organization), which can adopt the ordinary trademark protection. The owner of the intangible cultural heritage will apply for trademark application, after the success of registration, and then the individual becomes trademark proprietor. The second is the intangible cultural heritage belonging to particular ethnic or specific groups, which can choose protection of geographical indications. Most of the intangible cultural heritage belongs to a particular group, which has the characteristics of collective subject. Such intangible cultural heritage will encounter some obstacles for adopting the common trademark right protection mode. In addition, the regional characteristics of the intangible cultural heritage determine that its right is non-transferable, which contradicts to the transferability of common trademark. If it adopts protection mode of geographical indications, it can overcome these obstacles. The so-called geographical indications are the indications that indicate that the commodity comes from a certain region and the specific quality, reputation or other characteristics of the goods mainly determined by natural factors or human factors of the area. As it can be seen from the above concept, the geographical indications are the same with intangible cultural heritage. Both have the regional characteristics; while geographical indications pay attention to natural factors, it also emphasizes the human factor, which also fit into the culture of intangible cultural heritage. In addition, regionalism of geographical indications in turn determines non-transferability of its rights and the collectivism of right subject, which are also the characteristics of intangible cultural heritage. We can say that geographical indications right is the type of intellectual property that integrate the most well with intangible cultural heritage and it can provide the most convenient intellectual property protection for intangible cultural heritage. 
There are now two ways for geographical indications protection in China: one is to obtain protection from "Trademark Law" by registering geographical indications as a collective trademark or certification mark; the second is to obtain geographical indications protection by submit application to General Administration of Quality Supervision based on the "Geographical Indications Protection Products Regulations".

\section{Patent Protection of Intangible Cultural Heritage}

\section{The Obstacles for Intangible Cultural Heritage Patent Protection.}

The three basic requirement of modern patent system for patent granting object are novelty, creativity and practicality. Intangible cultural heritage may be able to meet the practical, but it is difficult to meet the requirements of novelty and inventive. The novelty in "Patent Law" mainly refers to that the of the invention or utility model do not belong to existing knowledge that is known by the public, the design does not belong to existing design that is known by the public. How intangible cultural heritage has integrated into the daily life of specific groups and entered into the public domain and is well known to everyone in the long period of inheritance. The creativity in "Patent Law" means that compared with the existing technology, the invention has prominent substantive features and notable progress. Some intangible cultural heritage have formed unique features in the course of inheritance from generation to generation, but compared to existing technology, it is difficult to have a significant progress. So China's current Patent Law is also unable to satisfy patent protection of intangible cultural heritage.

It should be noted that if the inheritors of intangible cultural heritage innovate and further study intangible cultural heritage and then form a new technology or process, which meet the three requirements of patent, of course, they can apply for a patent. For example Li Guoshun who is the inheritor of Wuliyuan preserved egg manufacturing skill in Xiu Wu county, He Nan province applied patent for his self-created preserved eggs sauce and color-painted preserved eggs.

\section{The Choice of Realistic Ways--Protection over Trade Secret Right.}

The trade secret share a great similarity with patent right and the right contents of the two are also very similar. However, trade secret has some characteristics that patents do not have, which is more suitable for the protection of intangible cultural heritage: first, the protection scope of trade secret is wider than patents. Some business information that does not have the creativity can also obtain trade secret protection, meaning that trade secrets do not require creativity, which provides the possibility for protection of intangible cultural heritage; secondly, there is no protection term for trade secrets, as long as the information has been kept secret, rights holders can always enjoy the exclusive right, which also meets the nature of long-term protection of intangible cultural heritage. Finally, trade secret rights subject is diverse, namely a trade secret can be possessed simultaneously by multiple subjects and each subject respectively enjoy the full right, which is consistent with the collectivism of the subject of intangible cultural heritage $\mathrm{f}$. Of course, not all intangible cultural heritages can receive the protection of trade secrets. The primary conditions for constituting a trade secret is that the right subject takes measures for keeping secrets and the information is not known to the public. Therefore, among the intangible cultural heritages, only those traditional crafts, traditional formula, skills, traditional remedy and so on which are kept in secret can obtain trade secret protection.

\section{References}

[1] Convention for the Safeguarding of the Intangible Cultural Heritage, article 2.

[2] Zhen Youde. Intellectual Property Law. Higher Education Press, 2004 edition, p.5

[3] Liu Chuntian. Intellectual Property Law. Peking University Press, 2007 edition, p.46

[4] Trademark Act, article 16.

[5] Patent Law, article 22. 
[6] Bai Huiyin. Study on the intellectual property protection of intangible cultural heritage-on the case of He Nan. Journal of Anyang Institute of Technology,2012(5) 